\title{
Attitude and perception of orthodontic patients to orthodontic treatment time and accelerated orthodontics.
}

\author{
${ }^{1}$ Umeh O.D., ${ }^{1}$ Isiekwe I.G, ${ }^{1}$ daCosta O.O., ${ }^{1}$ Sanu O.O., ${ }^{1}$ Utomi I.L., Izuka M.
}

Department of Child Dental Health, Lagos University Teaching Hospital Idi-Araba, Lagos, Nigeria. Faculty of Dental Sciences, College of Medicine, University of Lagos, Idi-araba, Lagos, Nigeria.

\begin{abstract}
Objectives: The purpose of this study was to evaluate the attitude and perception of orthodontic patients to the duration of orthodontic treatment and the procedures for accelerating orthodontic tooth movement.

Methods: This was a cross-sectional analytical study. The study population was made up of patients undergoing fixed appliance orthodontic treatment at the Orthodontic Unit of the Lagos University Teaching Hospital. A convenience sampling technique was used and data collection was via selfadministered questionnaires and an information sheet. The questionnaires assessed patients' knowledge of accelerated orthodontic procedures as well as their perception of orthodontic treatment time and willingness to undergo some accelerated orthodontic treatment procedures. The procedures evaluated included corticotomy, piezocision, micro-osteoperforation, laser therapy, local administration of injections and use of vibrations.

Results: One hundred orthodontic patients ( $n=100$, adolescents, 46\%; adults, 54\%) were surveyed comprising 36 males and 64 females. Most of the participants $(88 \%)$ had never heard of accelerated orthodontics. A majority of respondents $(75 \%)$ believed that orthodontic treatment time was too long, and were willing to undergo additional procedures to reduce treatment time (81\%). Subjects' willingness to undergo the procedures were inversely proportional to the degree of its invasiveness for all groups, with at least a third of the patients willing to accept a $10 \%$ increase in treatment fees for a reduction in treatment time across all techniques surveyed.

Conclusion: The orthodontic patients surveyed considered treatment time protracted and were interested in undergoing adjunctive orthodontic procedures to accelerate tooth movement, with a consequent increase in treatment cost. They, however, had a limited knowledge of the different methods of accelerating orthodontic treatment.
\end{abstract}

Key words: Accelerated orthodontics, orthodontic treatment time

INTRODUCTION: Orthodontic treatment is now increasingly sought by adults and children with the aim of improving oral function, aesthetics and psychosocial reasons ${ }^{1,2,3}$. One of the major limitations of orthodontic treatment which is of concern to patients (especially the adults) and the orthodontists is the prolonged treatment time $e^{1,4}$. Other complications associated with orthodontic tooth movement include caries, gingival recession, root resorption, white spot lesions (demineralization) and tooth mobility ${ }^{1,5,6,7}$. The average duration of comprehensive orthodontic fixed

\section{Correspondence: Umeh O.D.}

Department of Child Dental Health, Lagos

University Teaching Hospital Idi-Araba, Lagos.

E-Mail: umehod@gmail.com

Tel: +2348081412492

Received: 09/05/2019

Accepted: 07/05/2020

http://doi.org/10.4314/ajoh.v9i2.2 appliance treatment ranges from 2 to 3 years depending on the complexity of malocclusion ${ }^{8}$. Shortening orthodontic treatment time may reduce some of the complications associated with treatment and likely increase patient satisfaction ${ }^{6}$.

Several adjunctive procedures have been proposed to accelerate tooth movement to reduce treatment time. Some of these include the local administration of certain biomodulators/drugs ${ }^{9,10}$, the use of physical stimulation methods such as low level laser therapy ${ }^{11}$ and vibration, ${ }^{12}$ and various surgical techniques such as corticotomy, piezocision and micro osteoperforation $^{4,8,13}$.

The local administration of certain biomodulators to accelerate tooth movement have been investigated in animals. Some of the substances include vitamin $\mathrm{D}^{3,14}$, prostaglandins ${ }^{15}$, parathyroid hormones, relaxin and osteocalcin with variable results and side effects ${ }^{10,13,16}$. Although these methods of accelerating tooth 
movement looks promising, further research is needed to ascertain efficacy, dosage, safety and side effects ${ }^{16}$. Low-level laser therapy affects bone cell activity, with an increased osteoblastic cell surface and osteoid width around irradiated areas ${ }^{11,17,18}$. Previous literature on the effect of low-level laser therapy on tooth movement is howeverinconsistent ${ }^{11,17,18}$. This may be due to variations in interval between radiation and dosage in the different studies ${ }^{17}$.

A recent human study by Cruz et $\mathrm{al}^{11}$, demonstrated significant accelerated orthodontic tooth movement during canine retraction on 11 orthodontic patients. A randomized controlled trial by Mohammed et $\mathrm{al}^{18}$ similarly reported the efficacy of low level laser therapy in accelerating tooth movement in the leveling and alignment stage in orthodontic patients.

The use of vibration as a means of accelerating orthodontic tooth movement has gained a lot of popularity in recent years with the advent of AcceleDent. Its efficacy however has remained controversial. While a literature review of accelerated orthodontic procedures in 2014 reported a 30 to $40 \%$ reduction in orthodontic treatment time with physical/mechanical bone stimulation ${ }^{13}$, more recent studies have reported otherwise, with no observable acceleration of orthodontic tooth movement ${ }^{19,20}$.

The physical/ stimulation methods (low intensity laser and vibratory stimulus) of accelerating tooth movement are considered noninvasive and have been reported to accelerate tooth movement by $28-60 \%{ }^{16,21,22}$. Surgical methods proposed for reducing orthodontic treatment time include corticotomy, piezocision and osteoperforation/alveocentesis. These surgical methods effect tooth movement by a process called regional acceleratory phenomenon ${ }^{6,13}$. Regional acceleratory phenomenon is a natural localized reaction of soft and hard tissues in response to an injury, and is associated with increased perfusion, bone turnover and decreased bone density ${ }^{23,24}$.

Corticotomy as a means of accelerating orthodontic treatment has gained popularity over the years ${ }^{6}$, with reported success both in human and animal studies. This procedure requires raising a flap and subsequent making of bony incisions in the cortical bone without extending to the medullary bone ${ }^{7}$, hence is considered invasive. Piezocision, however, is a relatively less invasive flapless form of corticotomy which involves the placement of vertical interproximal incisions apical to the interdental papilla using an ultrasonic tool on the buccal cortical plate inducing bone injury ${ }^{6}$.
Despite these numerous methods aimed at reducing treatment time, the extent of acceptability among orthodontists and patients is yet to be widely investigated. Uribe et $\mathrm{al}^{6}$. assessed the perception of patients and orthodontists on the need and cost of additional procedures to reduce orthodontic treatment time in an American population. Their findings showed that both patients and orthodontists were willing to adopt procedures to reduce treatment time at an additional cost. More studies amongst varied orthodontic populations, including recent accelerated orthodontic procedures are required however to add to the body of evidence.

The objectives of this study were therefore to evaluate the knowledge, attitude and perception of orthodontic patients to treatment time and accelerated orthodontic procedures in a tertiary Health institution in West Africa. It also aimed to compare the knowledge and attitude to accelerated orthodontics between the adolescents and adults seeking orthodontic treatment

\section{METHODS}

Ethical approval was obtained from the Health Research Ethics Committeeof Lagos University Teaching Hospital Idi-Araba, Lagos Nigeria before the commencement of the study. A total of 100 patients (46 adolescents and 54 adults)undergoing fixed appliance orthodontic therapy at the Orthodontic Clinic of the Lagos University Teaching Hospital Idi-Araba, Nigeria were recruited. A convenience sampling technique was used. Adolescents were considered to be subjects between the ages of 10 to 19years; and adults were subjects above 19 years of age (WHO).

This was a cross-sectional analytical study. Data collection was via self-administered questionnaires and pictorial information sheets (showing the different accelerated orthodontic procedures) were used to obtain relevant information from participants. These were administered by the primary investigator (O.D.U). Informed consent and assent were fully obtained before completion of the questionnaire. The questionnaire contained information on participants' biodata, duration of time on treatment, estimated treatment time, desired treatment time, questions on awareness of accelerated orthodontic treatment and their attitude towards accepting it as an orthodontic treatment adjunct. Their willingness to accept an increase in treatment cost for a reduction in treatment 
Table 1: Age and gender distribution of the study population

Variable

\begin{tabular}{llllll}
\hline Age & & & & & \\
Mean Age \pm SD & $14.33 \pm 2.8$ & $26.6 \pm 6.33$ & 21.08 & & \\
Median & 14 & 26 & 20 & \\
Range & $11-18$ & $19-51$ & $11-51$ & & \\
\hline Sex & & & & 3.45 & 0.063 \\
Female & $25(54.3)$ & $39(72.2)$ & $64(64)$ & & \\
Male & $21(45.7)$ & $15(17.8)$ & $36(36)$ & &
\end{tabular}

Table 2: Treatment duration, expectations and desires

\begin{tabular}{|c|c|c|c|c|c|}
\hline & Adolescents & Adults & Total & & \\
\hline Variable & Freq (\%) & Freq $(\%)$ & Freq $(\%)$ & $x^{2}$ & $\mathrm{P}$ \\
\hline \multicolumn{6}{|c|}{ Years of treatment } \\
\hline$<1 \mathrm{yr}$ & $15(32.6)$ & $17(31.5)$ & $32(32)$ & \multirow{3}{*}{1.20} & \multirow{3}{*}{0.547} \\
\hline $1-3 y r s$ & $20(43.5)$ & 19(35.2) & $39(39)$ & & \\
\hline$>3 y r s$ & $11(23.9)$ & $18(33.3)$ & $29(29)$ & & \\
\hline \multicolumn{6}{|c|}{ Treatment takes too long } \\
\hline Agree & $29(63.0)$ & $46(85.2)$ & $75(75)$ & \multirow{3}{*}{10.03} & \multirow{3}{*}{0.007} \\
\hline Disagree & $1(0.02)$ & $3((5.5)$ & $4(4)$ & & \\
\hline Neutral & $16(34.78)$ & $5(9.3)$ & $21(21)$ & & \\
\hline \multicolumn{6}{|c|}{ How long do you expect } \\
\hline \multicolumn{6}{|c|}{ Treatment to last? } \\
\hline$<12$ mths & $13(28.3)$ & $14(25.9)$ & $27(27)$ & \multirow{3}{*}{1.72} & \multirow{3}{*}{0.422} \\
\hline $12-24 \mathrm{mths}$ & $23(50.0)$ & $33(61.1)$ & $56(56)$ & & \\
\hline$>24 \mathrm{mths}$ & $10(21.7)$ & $7(12.9$ & $17(17)$ & & \\
\hline \multicolumn{6}{|c|}{$\begin{array}{l}\text { Desired treatment } \\
\text { duration. }\end{array}$} \\
\hline$<6 \mathrm{mths}$ & $8(17.4)$ & $8(14.8)$ & $16(16)$ & & \\
\hline $6-12$ mths & $17(36.9)$ & $23(42.6)$ & $40(40)$ & & \\
\hline $13-18$ mths & $13(28.3)$ & $13(24.1)$ & $26(26)$ & 3.34 & 0.501 \\
\hline $19-24$ mths & $8(17.4)$ & $7(12.9)$ & $15(15)$ & & \\
\hline$\geq 24 \mathrm{mths}$ & $0(0)$ & $3(5.5)$ & & & \\
\hline
\end{tabular}

$\chi^{2}=$ chi squared,Freq $(\%)=$ frequency $($ percentage) 
Table 3: Subjects' knowledge and acceptance of accelerated orthodontic treatment procedures

\begin{tabular}{llllll}
\hline Variable & $\begin{array}{l}\text { Adolescents } \\
\text { Freq(\%) }\end{array}$ & $\begin{array}{l}\text { Adults } \\
\text { Freq(\%) }\end{array}$ & $\begin{array}{l}\text { Total } \\
\text { Freq(\%) }\end{array}$ & $\chi^{2}$ & P \\
\hline $\begin{array}{l}\text { Heardabout } \\
\text { acceleratedorthodontic }\end{array}$ & & & & & \\
treatment & & & & & \\
Yes & $5(10.9)$ & $7(13)$ & $12(12)$ & 0.030 & 1.000 \\
No & $41(89.1)$ & $47(87)$ & $88(88)$ & & \\
Willing to undergo & & & & & \\
$\begin{array}{l}\text { additional orthodontic } \\
\text { procedure }\end{array}$ & & & & & \\
Yes & $35(76)$ & $46(85.2)$ & $81(81)$ & 1.33 & 0.310 \\
No & $11(24)$ & $8(14.8)$ & $19(19)$ & & \\
$\begin{array}{l}\text { Payment Method } \\
\text { Out of pocket }\end{array}$ & $45(97.2)$ & $53(98)$ & $98(98)$ & 0.909 & 1.000 \\
Insurance & $1(2.8)$ & $1(2)$ & $2(2)$ & & \\
\hline
\end{tabular}

Table 4: Subjects' willingness to undergo different accelerated orthodontic procedures

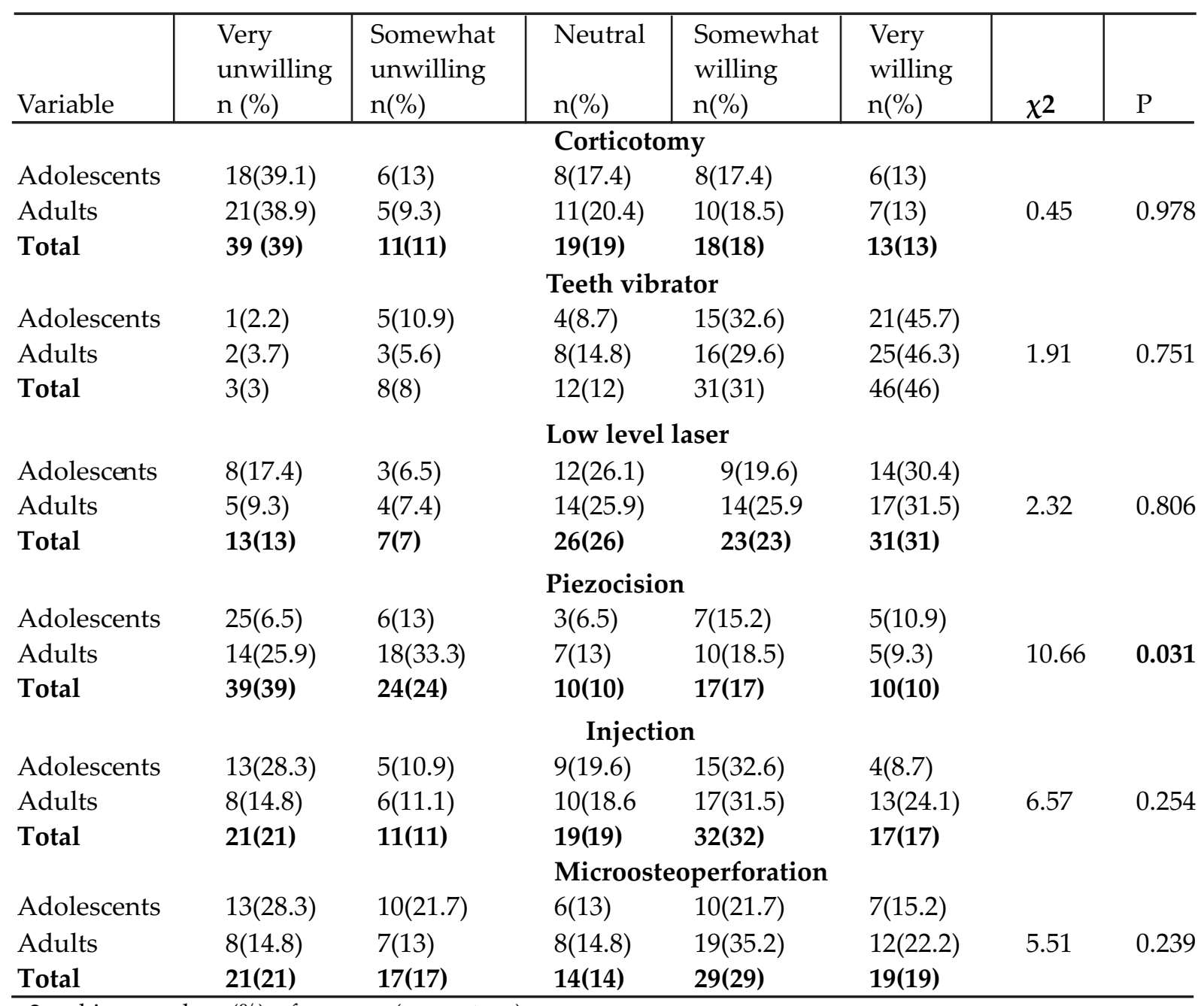

$\chi^{2}=$ chi squared, $\mathrm{n}(\%)=$ frequency(percentage) 
Table 5 Subjects' ranked preference for different procedures with a consequent $25.30 \%$ increase in treatment time

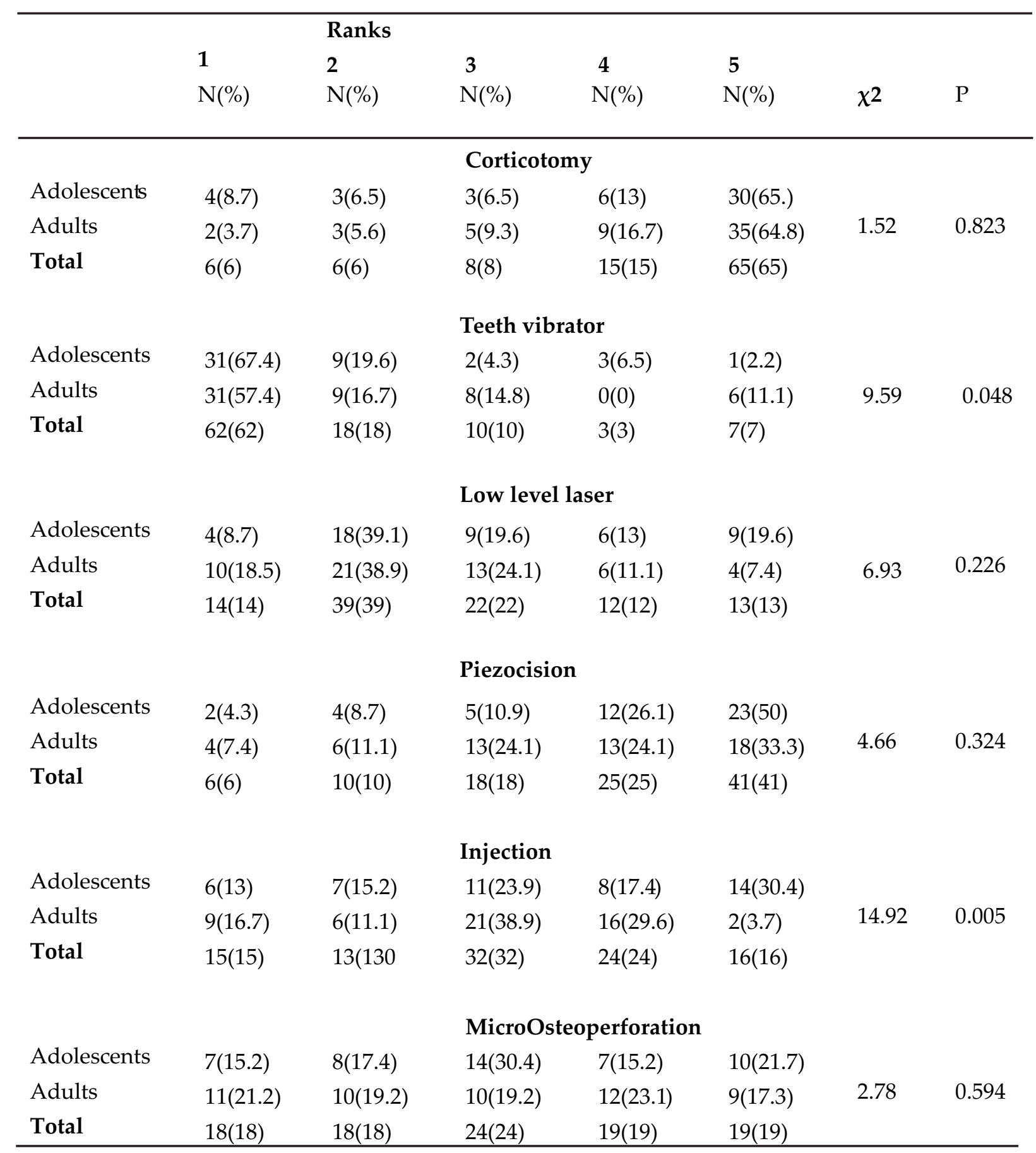


Table 6: Percentage fee increase for reduction in treatment time

\begin{tabular}{|c|c|c|}
\hline Variable & Frequency & Percent \\
\hline \multicolumn{3}{|c|}{ Corticotomy } \\
\hline $10.00 \%$ & 11 & 35.5 \\
\hline $20.00 \%$ & 7 & 22.6 \\
\hline $30.00 \%$ & 9 & 29.0 \\
\hline $40.00 \%$ & 2 & 6.5 \\
\hline $50.00 \%$ & 2 & 6.5 \\
\hline Total & 31 & 100.0 \\
\hline \multicolumn{3}{|c|}{ Teeth Vibrator } \\
\hline $10.00 \%$ & 37 & 48.1 \\
\hline $20.00 \%$ & 18 & 23.4 \\
\hline $30.00 \%$ & 17 & 22.1 \\
\hline $40.00 \%$ & 3 & 3.9 \\
\hline $50.00 \%$ & 2 & 2.6 \\
\hline Total & 77 & 100.0 \\
\hline \multicolumn{3}{|c|}{ Low Level Laser } \\
\hline $10.00 \%$ & 24 & 44.4 \\
\hline $20.00 \%$ & 17 & 31.5 \\
\hline $30.00 \%$ & 10 & 18.5 \\
\hline $40.00 \%$ & 2 & 3.7 \\
\hline $50.00 \%$ & 1 & 1.9 \\
\hline Total & 54 & 100.0 \\
\hline \multicolumn{3}{|c|}{ Piezocision } \\
\hline $10.00 \%$ & 13 & 48.1 \\
\hline $20.00 \%$ & 7 & 25.9 \\
\hline $30.00 \%$ & 4 & 14.8 \\
\hline $40.00 \%$ & 2 & 7.4 \\
\hline $50.00 \%$ & 1 & 3.7 \\
\hline Total & 27 & 100.0 \\
\hline \multicolumn{3}{|c|}{ Injection } \\
\hline $10.00 \%$ & 18 & 36.7 \\
\hline $20.00 \%$ & 12 & 24.5 \\
\hline $30.00 \%$ & 11 & 22.4 \\
\hline $40.00 \%$ & 4 & 8.2 \\
\hline $50.00 \%$ & 4 & 8.2 \\
\hline Total & 49 & 100.0 \\
\hline \multicolumn{3}{|c|}{ Micro Osteoperforation } \\
\hline $10.00 \%$ & 21 & 43.8 \\
\hline $20.00 \%$ & 10 & 20.8 \\
\hline $30.00 \%$ & 12 & 25.0 \\
\hline $40.00 \%$ & 2 & 4.2 \\
\hline $50.00 \%$ & 3 & 6.3 \\
\hline Total & 48 & 100.0 \\
\hline
\end{tabular}


time was also assessed. The accelerated orthodontic procedures evaluated were local administration of biomodulators, use of physical stimulation such as low levellaser, use of vibration (AccelDent), surgical procedures such aspiezocision, microosteoperforation and corticotomy. The information sheets were given to the patients to educate them on the accelerated orthodontic procedures prior to filling the questionnaire. This contained a brief description of the procedures with an accompanying pictorial illustration. Patients below the age of 10 years and those with craniofacial anomalies and special health care needs were excluded from the study.

Statistical analysis was performed using IBM SPSS software version 22. Simple descriptive statistics was used to summarize the data. The findings were presented in frequency tables and cross tabulations to examine relationship between variables. Test of significance were evaluated using Chi-square test and Fishers exact $\mathrm{p}$ value where appropriate. A p-value of $<0.05$ was considered significant for all statistical analysis.

\section{RESULTS}

A total of one hundred patients participated in the study, comprising 36\% (36) males and $64 \%$ (64) females. Furthermore, $46 \%$ (46) of the patients were adolescents while $54 \%$ (54) were adults. The subjects' age ranged from 11 to 51 years with mean adolescent and adult ages of $14.33 \pm 2.8$ and $26.6 \pm 6.33$ respectively. The total mean age of the study population was 21.08years with a median of 20years (Table I). There was a higher female predominance in both adult and adolescent subgroups, although statistically insignificant $(\mathrm{P}=0.063)$ (Table I).

Table II reports the duration ofcomprehensive orthodontic treatment of the study participants. Out of the 100 subjects recruited, $39 \%$ had treatment duration of 1 to 3 years, and 29\% greater than 3 years, predominantly adults; however there was no statistically significant difference in treatment duration between the adult and adolescent subgroup $(\mathrm{p}=0.547)$. Majority of the respondents in the study $(75 \%)$ consequently considered the orthodontic treatment duration to be too long, while the remaining $21 \%$ and $4 \%$ neutral considered it adequate respectively. The adult subgroup was significantly more dissatisfied with treatment duration when compared to the adolescents ( $\mathrm{p}=0.007$ ) (Table II).

Responding to the question "How long did you expect your treatment to last", $83 \%$ of the subjects said that at the start of treatment, they had expected treatment duration of 24 months or less. Only $17 \%$ anticipated a treatment time of greater than 24 months.

Responses obtained however revealed a desired treatment time of not greater than 12 months among $56 \%$ of the study populationwhile about $26 \%$ and $15 \%$ desired treatment times of 13-18months and 19-24 months respectively. Only 3\% of the respondents desired orthodontic treatment time to exceed 24 months. There was no statistically significant difference in theresponses between the adults and adolescents population $(\mathrm{p}=0.501)$.

With respect to the questions on the knowledge and acceptance of accelerated treatment procedures, it was observed that most of the respondents had never heard of accelerated orthodontics $(88 \%)$, but were willing to undergo the procedures to reduce treatment time $(81 \%)$. There was no statistically significant difference between the responses of the adults and adolescents ( $\mathrm{p}=1.000, \mathrm{P}=0.310$ ) (Table III).

An assessment of the study subjects' willingness to undergo different accelerated orthodontic procedures revealed thirty one percent of respondents willing to undergo the corticotomy procedure, while the remaining $69 \%$ were either neutral or unwilling to accept it as a treatment adjunct (Table IV).

Approximately $30 \%$ of the respondents were willing to undergo the piezocision procedure as a treatment adjunct, with the remaining $10 \%$ and $63 \%$ being neutral and unwilling to undergo the procedure respectively. The adults were significantly more willing to undergo these procedures than adolescents. ( $\mathrm{P}=0.031$ ) (Table III).

An acceptance level of approximately $50 \%$ was observed with the microosteoperforation procedure with an additional $14 \%$ of the respondents being neutral to undergoing the procedure.

The willingness to accept vibration and low level laser as a treatment adjunct by the respondents were $77 \%$ and $54 \%$ respectively; with no statistically significant difference between responses from the adult and adolescent subgroups $(\mathrm{P}=0.751,0.860)$.

Forty-nine $(49 \%)$ percent of the respondents were willing (very willing \& somewhat willing) to adopt the local administration of biomodulators as a treatment adjunct to accelerate orthodontic treatment procedure; while $32 \%$ were unwilling, the remaining $19 \%$ were neutral.

A set of questions required the respondents to rank the 
5 different procedures $1-5$ in the order of preference; where 1 signified most willing and 5, most unwilling with a resultant 25-30 reduction in treatment time. The responses showed the use of tooth vibrators to be the most preferred treatment procedure $(62 \%)$, while corticotomy was the least preferred (65\%) (Table V).

A majority of the subjects recruited paid for their orthodontic treatment out of pocket $(98 \%)$ and at least a third was willing to accept a $10 \%$ increase in treatment fees for all accelerated orthodontic techniques surveyed

\section{DISCUSSION}

The need for the ongoing research to develop new innovations in orthodontics to reduce treatment time cannot be overemphasized. The duration of comprehensive orthodontic treatment is approximately 2 to 3 years depending on case complexity. ${ }^{8}$ This study reported treatment duration of greater than 3 years in approximately $30 \%$ of the respondents. It was therefore not surprising that about three-quarters of the respondents considered treatment duration too long, with the adults being more dissatisfied $(85.2 \%)$ than the adolescents $(62 \%)$. This finding is at variance with a previous study ${ }^{6}$ where adults were neutral to the treatment duration but the adolescents considered it too long. This variation in findings between the two may be attributed to the significantly longer treatment duration in the current study when compared to the former; with more adults in treatment for longer than 3 years. The patients' dissatisfaction with duration of treatment expressed by most of the respondents in our study may be that most of them $(83 \%)$ had expected treatment duration of not greater than 24 months as patients were informed at the start of treatment that orthodontic treatment duration was 18 to 24 months.

Despite treatment expectations and durations, both the adolescents and adults desired a treatment time of between six to eighteen months. This is in agreement with a previous report with none of the adolescents desiring treatment duration of greater than 24 months ${ }^{6}$. When the knowledge of accelerated orthodontics was evaluated, most of the respondents were unaware of the concept of accelerated orthodontics. This may be because accelerated orthodontics techniques are not routinely done in the institution and therefore was not offered as a treatment option at the start of treatment. The accelerated orthodontic techniques were not offered due to insufficient evidence regarding the efficacy of the different accelerated orthodontic procedures or deficient manpower ${ }^{12-16}$. Furthermore, there is limited expertise in this area by the Orthodontists at this center and unavailability of the materials required for carrying out these techniques. Thus, there is a need for further studies to assess the practice and limiting factors to accelerated orthodontic procedures among orthodontists in our environment. It is noteworthy that majority of the patients were willing to adopt this concept, if it promised a reduction in orthodontic treatment time.

When the respondents' willingness to adopt the various accelerated orthodontic techniques was evaluated, a similarity in the adults' and adolescents' responses was observed. The two subgroups showed a high acceptance level towards the use of vibrations and low level laser; with the surgical procedures; corticotomy, piezocision and micro osteoperforation not receiving as much acceptance. This may be attributed to the degree of invasiveness of the surgical procedures. It was observed that the less invasive the procedures were, the more likely the patients would accept it as a treatment adjunct and vice versa. This was in agreement with a previous study which reported patient preference for the minimally invasive procedures ${ }^{13}$.

Among the surgical procedures, micro osteoperforation was the most accepted while corticotomy was the least preferable. The use of injections although not as acceptable to the patients as the physical stimulation methods, was preferred to the surgical procedures.

When the individual preference for different procedures were assessed assuming it would proffer a consequent $25-30 \%$ reduction in treatment time, the order of preference in ascending order was as follows: corticotomy, piezocision, micro osteoperforation, injection, low level laser and the use of vibration. This order is very similar to the findings of Uribe etal ${ }^{6}$, although the use of low level laser and micro osteoperforation were not evaluated in that study. Interestingly, when the patients were informed that the surgical procedures were twice as effective in enhancing tooth movement compared to the use of vibration, their preferences remained unchanged. Extensive literature investigating the effect of vibration on tooth movement in recent years showed that it does not accelerate tooth movement. A multicentrerandomized control trial on the effect of 
vibration force on tooth movement showed that it had no effect on overall treatment duration, space closure or number of visits ${ }^{26}$. Similarly, Miles et $\mathrm{al}^{19}$ reported no significant difference when comparing the rate of space closure using the AcceleDent Aura versus no appliance in the maxillary arch in an adolescent population.

It was observed that over one third of the respondents were willing to accept only a $10 \%$ increase in treatment fees for a reduction in treatment time. Most of the subjects paid out of pocket for their treatment and may not easily accommodate further increase. Further evaluation revealed that the willingness to accept these procedures were directly proportional to perceived degree of invasiveness.

This study also has some limitations. It was a single centre study and was carried out in a public tertiary health institution and thus may not reflect the views of patients receiving orthodontic care in private clinics. The study however evaluated both old and newer techniques of accelerating tooth movement such as the use of low level laser and micro osteoperforation.
Unfortunately, paucity of data on the efficacy of the various accelerated orthodontic technique poses a major problem in treatment decision for orthodontists and patient information. Further research on the efficacy of the different treatment procedures in accelerating tooth movement, and its acceptability amongst orthodontists is suggested.

\section{CONCLUSION}

A majority of the patients surveyed reported that orthodontic treatment takes too long and had no previous knowledge of accelerated tooth movement procedures. However, most of the patients were willing to undertake accelerated orthodontic procedures, in order to reduce treatment time. The less invasive techniques were the most preferred acceleratory methods, with vibration being the most preferred technique and corticotomy the least. There is a need for further studies in this environment, to assess the perceptions and practice of accelerated orthodontics among Nigerian orthodontists...

\section{APPENDIX}

Information about the additional procedures discussed in the Questionnaire to reduce orthodontic treatment time (5):

\begin{tabular}{|c|l|}
\hline Procedure & \multicolumn{1}{|c|}{ Description } \\
\hline Corticotomy & $\begin{array}{l}\text { Cuts are made on the bone } \\
\text { surrounding the teeth after } \\
\text { raising a gum flap (See picture) to } \\
\text { increase the rate of tooth } \\
\text { movement. This will be done once } \\
\text { every 4 months. }\end{array}$ \\
\hline Teeth vibrator & $\begin{array}{l}\text { A device to be used in the mouth } \\
\text { 10 to 20 minutes daily which } \\
\text { vibrates the teeth with the orthod- } \\
\text { ontic appliances. }\end{array}$ \\
\hline
\end{tabular}




\begin{tabular}{|c|c|c|}
\hline Piezocision & $\begin{array}{l}\text { Instead of reflecting a flap, small } \\
\text { microcuts are made thru the gums } \\
\text { to increase the rate of tooth } \\
\text { movement }\end{array}$ & \\
\hline $\begin{array}{l}\text { Drug injected } \\
\text { around teeth }\end{array}$ & $\begin{array}{l}\text { Drugs injected around the teeth } \\
\text { as shown in the picture }\end{array}$ & \\
\hline $\begin{array}{l}\text { Low level laser } \\
\text { therapy }\end{array}$ & $\begin{array}{l}\text { This involves use of low energy } \\
\text { laser therapy }\end{array}$ & \\
\hline Micro osteoperforations & $\begin{array}{l}\text { This involves making small pun- } \\
\text { ctures on the gum }\end{array}$ & \\
\hline
\end{tabular}




\section{REFERENCES}

1. Aksakalli S, Calik B, Kara B,Ezirganli S. Accelerated tooth movement with piezocision and its periodontal-transversal effects in patients with Class II malocclusion. Angle Orthodontist 2016; 86(1):59-65.

2. Ackerman MB. Enhancement Orthodontics: Theory and Practice, $1^{\text {st }}$ Ed. WileyBlackwellMunksgaard;2007.

3. Mathews DP, Kokich VG. Managing treatment for the orthodontic patient with periodontal problems. SeminarsOrthod. 1997; 3:21-38.

4. Nimeri G, Kau CH, Nadia S, Abou-Kheir, Corona R. Acceleration of tooth movement during orthodontic treatment-A frontier in Orthodontics (A review). ProgressOrthod 2013; $14(1): 42$.

5. Sameshima GT, Sinclair PM. Predicting and preventing root resorption: Part II. Am J Orthod Dentofacial Orthop 2001; 119:511-5.

6. Uribe F, Soumya P, Allareddy V, Ravindra Nanda. Patients', parents', and orthodontists' perceptions of the need for and costs of additional procedures to reduce treatment time. Am J Orthod Dentofacial Orthop. 2014:145(4); 65-73.

7. Andrade I, Sausa ABS, Da Silva GG. New therapeutic modalities to modulate tooth movement. Dental Press Journal of Orthodontics 2014; 19(6): 123-133.

8. Long H, Pyakurel U, Wang Y, Liao L, Zhou Y, Lai L. Interventions for accelerating orthodontic tooth movement. Angle Orthodontist: 2013; 83(1):164-71.

9. Leiker BJ, Nanda RS, Currier GF, Howes RI, Sinha PK: The effects of exogenous prostaglandins on orthodontic tooth movement in rats. Am J Orthod. Dentofacial Orthop 1995, 108(4):380-8.

10. Krishnan V, Davidovitch $Z$. The effect of drugs o $\mathrm{n} \quad \mathrm{orthodontic} \quad \mathrm{tooth}$ movement.OrthodCraniofac Res 2006; 9(4):163-71.

11. Cruz DR, Kohara EK, Ribeiro MS, Wetter NU. Effects of low-intensity laser therapy on the orthodontic movement velocity of human teeth: a preliminary study. Lasers Surg Med2004;35(2):117-20.
12. Liu D. Acceleration of Orthodontic tooth movement by mechanical vibration. 2010 AADR Annual meeting Washington D.C.

13. Shevena S, Nayak U, Bhaskar V, Nayak. Accelerated orthodontics-A review. International Journal of Scientific Study 2014; 1(5):35-39.

14. Collins MK, Sinclair PM. The local use of vitamin $\mathrm{D}$ to increase the rate of orthodontic tooth movement. Am J Orthod 1988; 94(4):278-84.

15. Yamasaki K, Shibata Y, Imai S, Tani Y, Shibasaki Y, Fukuhara T.Clinical application of prostaglandin E1 (PGE1) upon orthodontic tooth movement.Am J Orthod 1984; 85(6):508-18.

16. King G. Biomedicine in orthodontics: From tooth movement to facial growth. Orthodontics \& Craniofacial Research 2009, 12: 53-58.

17. Seifi M, Atri F, Yazdani MM. Effects of lowlevel laser therapy on orthodontic tooth movement and root resorption after artificial socket preservation. Dental Research Journal. 2014; 11(1):61-66.

18. Mohammad MA. AlSayedH,Sultan K, Omar Hamadah.Low-level laser therapy effectiveness in accelerating orthodontic tooth movement: A randomized controlled clinical trial. Angle Orthodontist. 2017;87 (4):499-504

19. Miles P, Fisher E, Pandis N. Assessment of the rate of premolar extraction space closure in the maxillary arch with the AcceleDent Aura appliance versus no appliance in adolescents: A single-blind randomized clinical trial.Am J Orthod Dentofacial Orthop2018;153(1):8-14.

20. Katchooi M, Cohamin B, Tai S, Bayiri B, Spikerman C, Huang G. Effect of supplemental vibration on orthodontic treatment with aligners: A randomized trial. Am J Orthod Dentofacial Orthop. 2018;153 (3): $336-346$

21. Doshi-Mehta G, Bhad-patil WA. Efficacy of low intensity laser therapy in reducing treatment time and orthodontic pain; a 
clinical investigation. Am J Orthod Dentofacial Orthop 2012;141 (3):289-297

22. Nishimura M, Chiba M, Ohashi T, Sato M. Periodontal tissue activation by vibration : intermittent stimulation by resonance vibration accelerates experimental tooth movement in rats. Am J Orthod2008; 133 (4): 572-583.

23. Frost HM. The biology of fracture healing. An overview for clinicians. Part I. ClinOrthopRelat Res. 1989; 248:283-93.

24. Gantes B, Rathibun E, Anholm M. Effects on the periodontium following corticotomy- facilitated orthodontics. Case Reports. J Periodontol. 1990;61(4):234-7.

25. Health for the world's adolescents: a second chance in the second decade [Internet]. Geneva: World Health Organization; 2014. A $v$ a http://apps.who.int/adolescent/ seconddecade/(sited 2014 Sep 300.

26. Andrew TD, Neil RW, Spyridon NP, Nicola J. Effects of supplemental vibrational force on space closure, treatment duration, and occlusal outcome: A multicenter randomized clinical trial. Am J. Orthod 2018; 153 (4):469480 